\title{
Autism Spectrum Disorder in a Dental Office - A Review
}

\author{
Amarshree Amarnath Shetty ${ }^{1}$, Delisha Yesudas Fernandes ${ }^{2}$, Amitha Mahesh Hegde ${ }^{3}$ \\ 1, 2, 3 Department of Paediatric and Preventive Dentistry, AB Shetty Memorial \\ Institute of Dental Sciences, Mangalore, Karnataka, India.
}

\section{ABSTRACT}

Over the last few years there has been a growing interest to cater to the requirements of children with special health care needs, especially those with autism spectrum disorder (ASD). ASD is a neurodevelopmental condition characterized by limited communication skills and an obsessive need for structured patterns. Individuals with a genetic predilection to autism can be provoked by the various prenatal, natal, or post-natal environmental factors. Drugs such as thalidomide, valproic acid and consumption of antidepressants during pregnancy as well as high maternal age and viral infections are known to be prenatal triggers for autism. Autism affects 1 in every 110 children with a significant preponderance of boys to girls with a ratio of 4:1. According to Caries Risk Assessment tool (CAT) adapted by the American Academy of Paediatric Dentistry, children with ASD are at a high risk for dental caries due to their preference for carious food, pouching of food due to poor masticatory ability combined with inadequate maintenance of oral hygiene and help required for tooth brushing.

These children do not behave positively to sudden changes in their environment thus a dental operatory might be intimidating to them. A thorough understanding of the individual's needs of these patients along with combining various behaviour management techniques will help make their dental treatment a pleasant one.

This articles reviews literature on the aetiology and diagnosis of Autism Spectrum Disorder with a special emphasis on the health status and issues encountered while treating these children. This study is also an update on the various strategies such as using Applied Behaviour management approaches, Picture Exchange Communication System, Video Pedagogy, Social stories as well as pharmacological ways to communicate and also manage a child with ASD in the dental clinic.

\section{KEY WORDS}

Autism, Oral Health Status, Behaviour Management, Dental Management
Corresponding Author: Dr. Delisha Yesudas Fernandes, Department of Paediatric and Preventive Dentistry, AB Shetty Memorial Institute of Dental Sciences, Nitte (Deemed to Be University), Mangalore - 575018

Karnataka, India.

E-mail: delishayfernandes@gmail.com DOI: $10.14260 / j e m d s / 2021 / 398$

How to Cite This Article: Shetty AA, Fernandes DY, Hegde AM. Autism spectrum disorder in a dental office - a review. J Evolution Med Dent Sci 2021;10(26):1931-1939, 10.14260/jemds/2021/398

Submission 12-01-2021, Peer Review 01-05-2021, Acceptance 28-04-2021, Published 28-06-2021.

Copyright (c) 2021 Amarshree Amarnath Shettyet al. This is an open access article distributed under Creative Commons Attribution License [Attribution 4.0 International (CC BY 4.0)] 


\section{BACKGROUND}

Autism was first described in 1943 by a child psychiatrist named Leo Kanner. It is a combination of the Greek words 'Autos' and 'ismos' which means to be self-absorbed. The American Academy of Paediatric Dentistry (AAPD) states that children with special health care needs encompass children with autism spectrum disorder (ASD) which is a neurodevelopmental condition associated with reduced social capabilities, compromised communication skills, and monotonous or stereotyped behaviours. ${ }^{1}$ These characteristics have a great influence on one's ability to operate in areas of life such as school or work. As claimed by Diagnostic and Statistical Manual of Mental Disorders (DSM 5), Autism, Asperger disorder (AD), and pervasive developmental disorder - Not otherwise specified (PDD - NOS) fall under this umbrella term of ASD. ${ }^{2}$ Thus, specialized knowledge, as well as increased awareness and attention to the specific needs of the children with ASD are paramount while delivering appropriate dental care.

\section{HISTORY AND AETIOLOGY}

In 1747 a peculiar behaviour was noticed in a man named Hugh Blair who was described as tactless with an abnormal gaze although he was known to be friendly and affectionate. His striking features were obsessive, repetitive behaviour, echolalia, piling up twigs and always wanting to sit on the same bench. ${ }^{3}$ Because of these social deficits the term "silent madness" was coined.

In 1797, Itard in his behavioural initiative tried to shape the "Wild Boy of Aveyron" to help establish social bonds and persuaded him to speak through imitation.

Leo Kanner termed children with impaired communication skills as 'autistic psychopathy'. He noticed in these children, peculiar characteristic traits of being selfoccupied and lacking social and behavioural etiquettes with impaired communication skills. Kanner noticed that these symptoms were not identified until the year of life. ${ }^{4}$ Thus, he termed this reduced communication with absence of social emotions and a desire for continuity as 'early infant autism.' 5

Genetic and prenatal organic injury were known to be the etiological factors of Autism. Kanner further stated that lack of parental attention can trigger emotional refrigeration which could be highly pathogenic especially in the first few years of life making the child vulnerable to these social deficits. He established this emotional refrigeration to be the primary cause of autism. However, this refrigeration theory was refuted by Bernard Rimland, who stressed biological causes rather than psychological reasons. ${ }^{6}$

The accurate aetiology of ASD, whether it is caused due to environmental, genetic or neuropsychological factors is disputable. Various studies state that autism has a genetic predilection entailing up to 20 interrelated genes, present on chromosomes 2, 7, 15, 16 and 19 potentiating inheritance from one generation to the next. This finding was supported by various family and twin studies. Cytokine dysregulation, high maternally derived intrauterine androgen concentrations, de novo mutations, mitochondrial defects ${ }^{7,8,9}$ have also been stated to be the causes of ASD. Preponderance of males with the disorder suggests an $\mathrm{X}$ - linked disorder. ${ }^{10}$

Individuals with a genetic predilection to autism can be provoked by the various prenatal, natal or post natal environmental factors. Drugs such as thalidomide, valproic acid and consumption of antidepressants during pregnancy as well as high maternal age and viral infections are known to be prenatal triggers for autism. Prematurely born children with low birth weight leading to anaemia and folic acid deficiency are other risk factors for ASD. However, it is still debatable whether environmental factors merely act as triggers in children with an underlying genetic liability or are the main causative factors for autism. ${ }^{11}$

\section{INCIDENCE AND PREVALENCE}

According to the Centres for Disease Control and Prevention, individuals with Autism Spectrum Disorder (ASD) are the ones who display "impairments in social, communicative and behaviour development, that typically are present before the age of 3 years and are often accompanied by abnormalities in cognitive functioning, learning, attention and sensory processing". 12 According to National Health Interview Survey (NHIS) and National Survey of Children's Health (NSCH) by Centres for Disease Control and Prevention (CDC) the prevalence rate is 5.7 per 1000 and 5.5 per 1000 births respectively. ${ }^{13}$

Autism affects 1 in every 110 American children and 1 in 70 boys. ${ }^{14}$ In North-western India the spread of Autism is 0.9 / $1000^{15}$ while in Eastern India a prevalence rate of 0.23 / 1000 was reported. ${ }^{16}$ There is a significant preponderance of boys to girls with a ratio of $4: 1^{13,17}$ Looking at these statistics it is highly likely that dentists especially paediatric dentists will cater to the needs of patients with ASD. Thus, proper knowledge and comprehension of ASD is crucial to not only cater to their dental needs but also makes sure they have a pleasant experience in the dental clinic.

\section{DIAGNOSTIC CRITERIA}

Children with ASD are diagnosed by observing a child's behaviour and development. This process necessitates two progressive steps -

1. Developmental evaluation

2. Comprehensive Diagnostic evaluation.

Developmental evaluation:

The early signs of ASD are

- Avoiding eye contact

- Disinterest in social activities such as playing with other children or caretakers

- Limitations in communication with restricted use of words

- $\quad$ Shift from a routine is not well tolerated by them.

The American Academy of Paediatrics (AAP) recommends that all children be screened for developmental delays and disabilities during regular paediatric check-up at 9,18 , and 30 months of age and all children must be screened specifically for ASD at 18 and 24 months. 


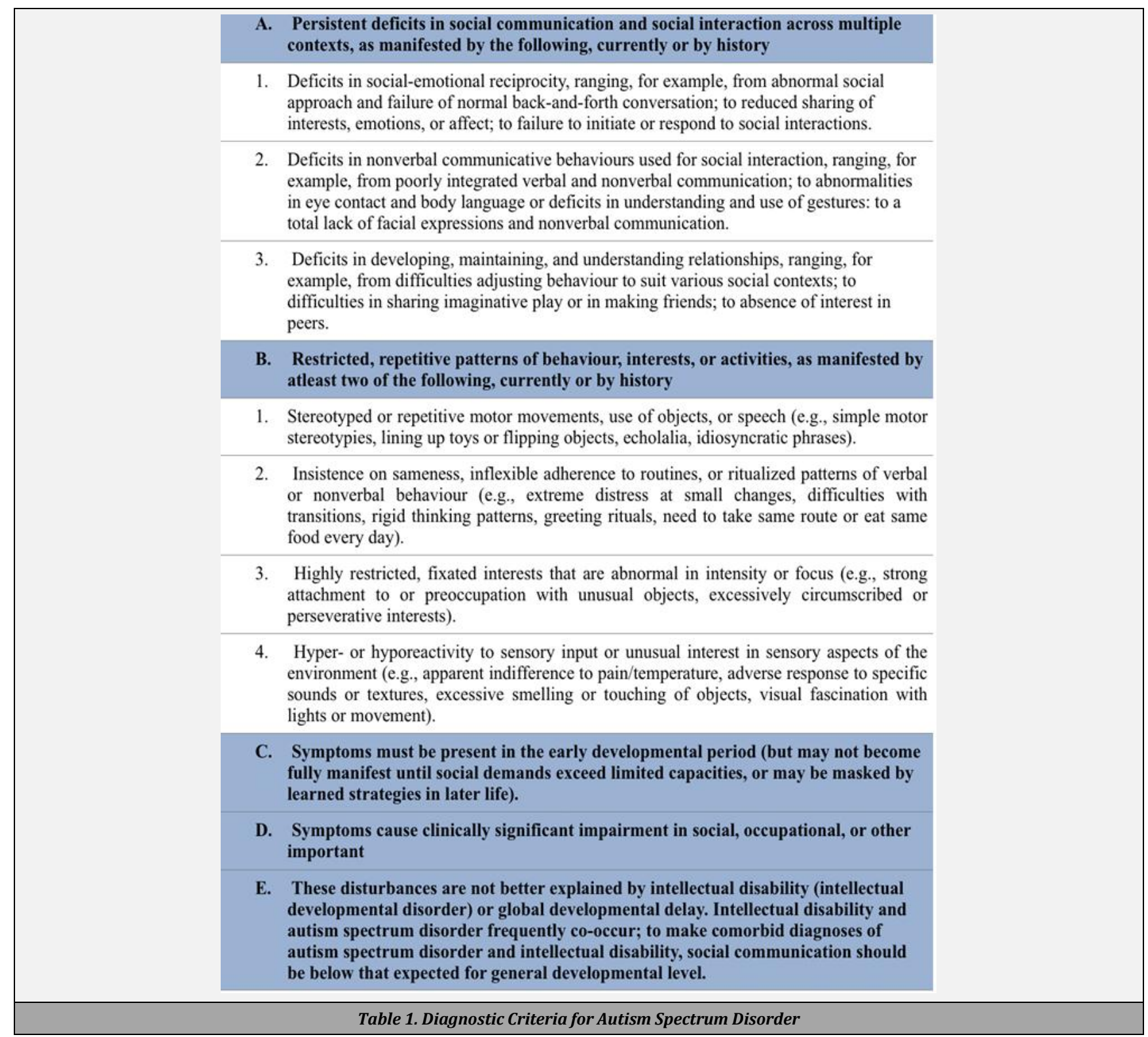

Additional screening is required for children who are at high risk of ASD (e.g., pre-term birth, low birth weight, parent / sibling with ASD). This screening helps to monitor the child's developmental milestones and evaluate if the children are learning basic skills such as communication, conduct, and actions at the appropriate time. The commonly used screening tools are modified checklist for autism in toddlers (M - CHAT), The ages and stages questionnaire (ASQ), screening tool for autism in toddlers and young children (STAT), communication and symbolic behaviour scales (CSBS) and parents' evaluation of developmental status (PEDS). Developmental screening tools do not provide conclusive evidence of the developmental delays and cannot be used to make diagnosis. Thus, a positive screening result should be followed up by a thorough assessment. As the child's first dental visit could be as early as 6 months of age, paediatric dentists should always be alert to identify these signs and send the child for further evaluation. ${ }^{17}$

\section{Comprehensive Diagnostic Evaluation}

The most important reason to obtain accurate diagnosis is that any other related conditions such as Rett's syndrome, fragile $\mathrm{X}$ syndrome, Landau - Kleffner can be identified, and the child could be eligible for support and resources from the government. Diagnostic tools rely on two main sources of information, the parents or caregivers' description of their child's development and the professional's observation of the child. Some examples of diagnostic tools are autism diagnosis interview - revised (ADI - R), autism diagnostic observation schedule - generic (ADOS - G), childhood autism rating scale (CARS), Gilliam autism rating scale - second edition (GARS 2). ${ }^{12}$

In addition to the above tools, a standardized diagnostic criterion described by DSM - 5, published by the American Psychiatric Association is utilized. (Table 1). Individuals with a well-established DSM - IV diagnosis of autistic disorder, Asperger's disorder, or pervasive developmental disorder not otherwise specified should be given the diagnosis of autism spectrum disorder. Individuals who have impaired social communication, but whose symptoms do not otherwise meet criteria for autism spectrum disorder, should be evaluated for social (pragmatic) communication disorder. ${ }^{17}$ 
ORAL HEALTH STATUS OF CHILDREN WITH ASD

According to caries risk assessment tool (CAT) adapted by the American Academy of Paediatric Dentistry, children with ASD are at a high risk for dental caries ${ }^{18}$ due to their preference for carious food, pouching of food due to poor masticatory ability combined with inadequate maintenance of oral hygiene and help required for tooth brushing. ${ }^{19}$ Symptoms such as irritability, presence of masochistic habits, agitation, aggression, delusions and repetitive behaviours are treated using anti-psychotic drugs which cause alterations in the salivary flow rate posing as a risk factor for caries. ${ }^{20}$ Methamphetamine is therapeutically consumed by children with autistic disorder which is known to be positively associated with rampant caries. ${ }^{21}$

Another characteristic oral finding seen in these children is gingivitis, various drugs which are used to control the manifestations of ASD are antidepressants, stimulants, antipsychotics that lead to gingivitis. ${ }^{22}$ Phenytoin induced hyperplasia could lead to retarded tooth eruption. ${ }^{23}$

Higher rates of periodontal diseases have been reported in autistic children.11,18,19,24,20 These children depend on their caregivers who are unqualified to render adequate oral care to others, leading to increase in plaque formation. ${ }^{11}$ On the contrary, some authors have stated a comparatively lower incidence of caries in children with ASD. 19,22,25 This finding is observed in children who are constantly under the care of their parents or caregivers who monitor their consumption of sugar rich foods.

Compromised dental status along with deleterious habits such as bruxism, lip and nail biting, thumb sucking, tongue thrusting or self-extraction of teeth may result in certain malocclusions. ${ }^{23,26}$ such as class II molar relationship, open bite, reverse over jet and spacing tendencies. The need for dental care and orthodontic treatment is higher in children with ASD.

The incidence of traumatic dental injuries is higher amongst children with ASD. The permanent maxillary central incisors are most commonly injured, and the type of injury is enamel fracture. Mouth guards can be recommended to prevent injuries.

\section{Barriers to Dental Treatment}

Due to the characteristic behavioural patterns of children with ASD, treating these children in a confined and new dental environment poses a big challenge for dentists. Classic behavioural reactions to unknown environment, individuals, and procedures along with difficulty in maintaining oral hygiene due to increased dependence of parents or caregivers to deliver home oral health care makes the dental management of children with ASD a herculean task. Autistic children do not tolerate exposure to foreign sounds and lights increasing their resistance to dental treatment leading to poor oral health. ${ }^{27}$

Dentists should have clear knowledge of the nature of this disorder, should be able to anticipate behavioural responses of the affected child and effectively modify the clinic based dental treatment and home oral care. In the developed countries, as high as $11 \%$ children's dental needs are found to be unmet. These authors reported that main barriers to dental care were child's behaviour, cost, and lack of insurance. ${ }^{28}$ Similarly, family income constraints and child's history of difficult behaviour in the dental office have been shown to be related to lack of regular dental care. This research also showed difficulty to find dentists with appropriate skills and the desire to work with disabled people. This was the most frequent reason given by the parents for not having a regular dental provider or checkups. ${ }^{29}$

A cross sectional case - control questionnaire study reported that dental access seemed to be more difficult for autistic children because of difficulty in travelling to the dental office. They also concluded that predicted negative behaviours were more frequent in the ASD group. ${ }^{29}$ Thus it is the responsibility of the paediatric dentist to ensure to make the child feel safe and address the individual needs of the children with ASD as this would shape their outlook and behaviours towards the future dental treatments.

\section{DENTAL MANAGEMENT CONSIDERATIONS}

\section{Pre-Appointment Counselling}

The dentist must schedule a meeting with the parents prior to the child's appointment to help the parents prepare the child as well as try and understand the behavioural patterns of the child. Paying attention to the individual needs of the child will not only ensure gaining their confidence but also will aid in collecting data about one's medical conditions and co morbidities if any. A video of the dental operatory along with the steps of the dental procedure can be shown to the child prior to their visit in order to induce familiarity.

Parents can also use picture cards explaining the dental procedure in order to ease the child prior to the dental treatment. Gluten is a type of protein found in wheat, rye and barley while Casein is a milk protein. Children with ASD usually possess a "leaky gut". This is a condition characterized by the intestine being permeable to even the large molecules of gluten and casein. These large molecules of gluten and casein enter into the systemic circulation and tend to have deleterious effects on cerebral function and impaired immune system. ${ }^{30}$

Thus, dietary modifications in the form of a Gluten free, casein - free (GFCF) diet is recommended in these patients. The effects of the GFCF diet include overall improvement of their ASD behaviour such as reduced hyperactivity, temper tantrums, obsessive habits, and reputations. ${ }^{31}$ Advancement in social behaviours like improved social responsiveness, eye contact, engagement, attention span, language production are also observed. ${ }^{32-35}$ Inclusion of probiotics, digestible proteins as well as digestible enzymes in the diet will help the digestive function of the child thus improving the overall behaviour.

Children with ASD should only be treated on prior appointment basis unless an emergency treatment needs to be delivered. The children shouldn't be made to wait for more than $10-15$ mins as it upsets them and can negatively affect their behaviour in the dental operatory. Because of the limited attention span of ASD patients, short and well-organized appointments should be planned. ${ }^{25}$ 


\section{Sensory Adaptive Dental Environment}

Children with ASD are reactive to strong light, sound as well as change in taste thus efforts should be made to adjust the dental clinic environment sensitively so as to avoid any unpleasant reaction by the child. Sensory adaptive dental environment is based on the Snoezelen environment which consists of a multisensory adapted environment based on the patients' needs which is directed towards visual, auditory, and tactile stimuli. Utilizing methods to adapt to the sensory environment in the dental office by minimizing noxious stimuli may highly benefit the children with sensory sensitivities. The dental operatory is kept calm and dark and thick curtains are placed all over windows. The direct overhead light of the dental chair is also switched off. Ambient lighting, consisting of dimmed upward reflective fluorescent light, in addition to slow moving, repetitive visual colour that is projected to the ceiling36is kept.

Music therapy is also associated with improvement in core symptoms of ASD. ${ }^{37}$ Audio stimulation in the form of rhythmic music should be played in the dental clinic in order to elicit a positive behaviour. In a study, modified papoose board in the form of a "friendly butterfly" (Figure 1) was used, which "hugged" the child tightly to reduce any possible disruptive movements. This not only helped to provide protective stabilization but also the benefits of deep pressure tactile stimulation which had a calming effect on children with ASD. 38 They concluded that children responded better in a sensory adapted environment as compared to a regular environment. ${ }^{36}$

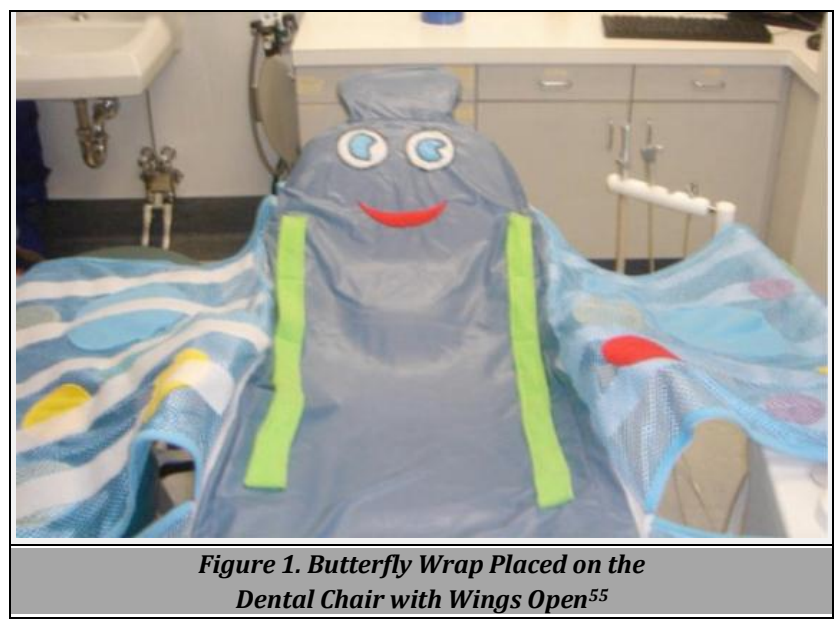

\section{APPLIED BEHAVIOUR ANALYSIS (ABA)}

It is a branch of psychology that deals with the exploration and shaping of human behaviour. This behaviour management technique, accepted by AAPD improves the dental etiquettes of children with limited communication as compared to conventional behaviour management practices. The use of ABA reduces the need for restraints, sedation and care delivered under general anaesthesia. It includes home based as well as in office preparation of the child. Home based preparation through ABA procedures include familiarization with dental instruments as well as teaching prerequisite skills such as "open your mouth" or "counting teeth". It is also an age accurate period to identify the child's likes and dislikes for objects that can be utilized as reinforces during the dental treatment. ${ }^{39}$ In the dental operatory, use of visual media in the form of picture cards or books can be done to enhance the effectiveness of the child's behaviour during dental and oral examination. ${ }^{40}$

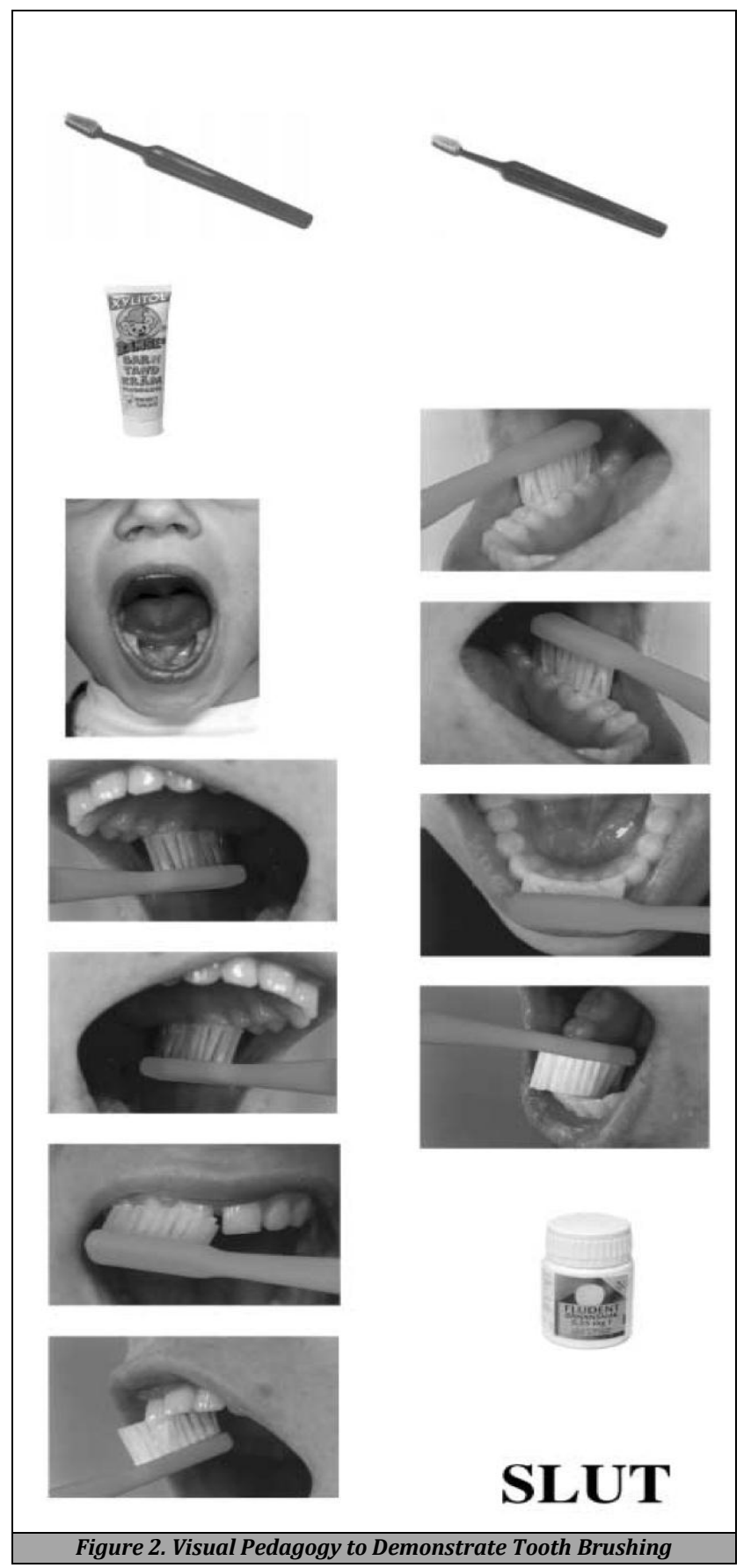

Reinforcement is one of the fundamental concepts of ABA, where there is an increase in positive behaviour as an outcome to a stimulus. Thus, positive, and negative reinforcements are associated with the commencement and termination of the stimulus respectively. A reward like a toy or praising may positively reinforce the child's behaviour on the dental chair. On the contrary, 'drilling the tooth' which could act as an unpleasant stimulus to the child can be controlled by performing the procedure for a present time like counting from 1 to 10 . Immediately after that, the procedure can be interrupted for a while. ${ }^{41}$ 


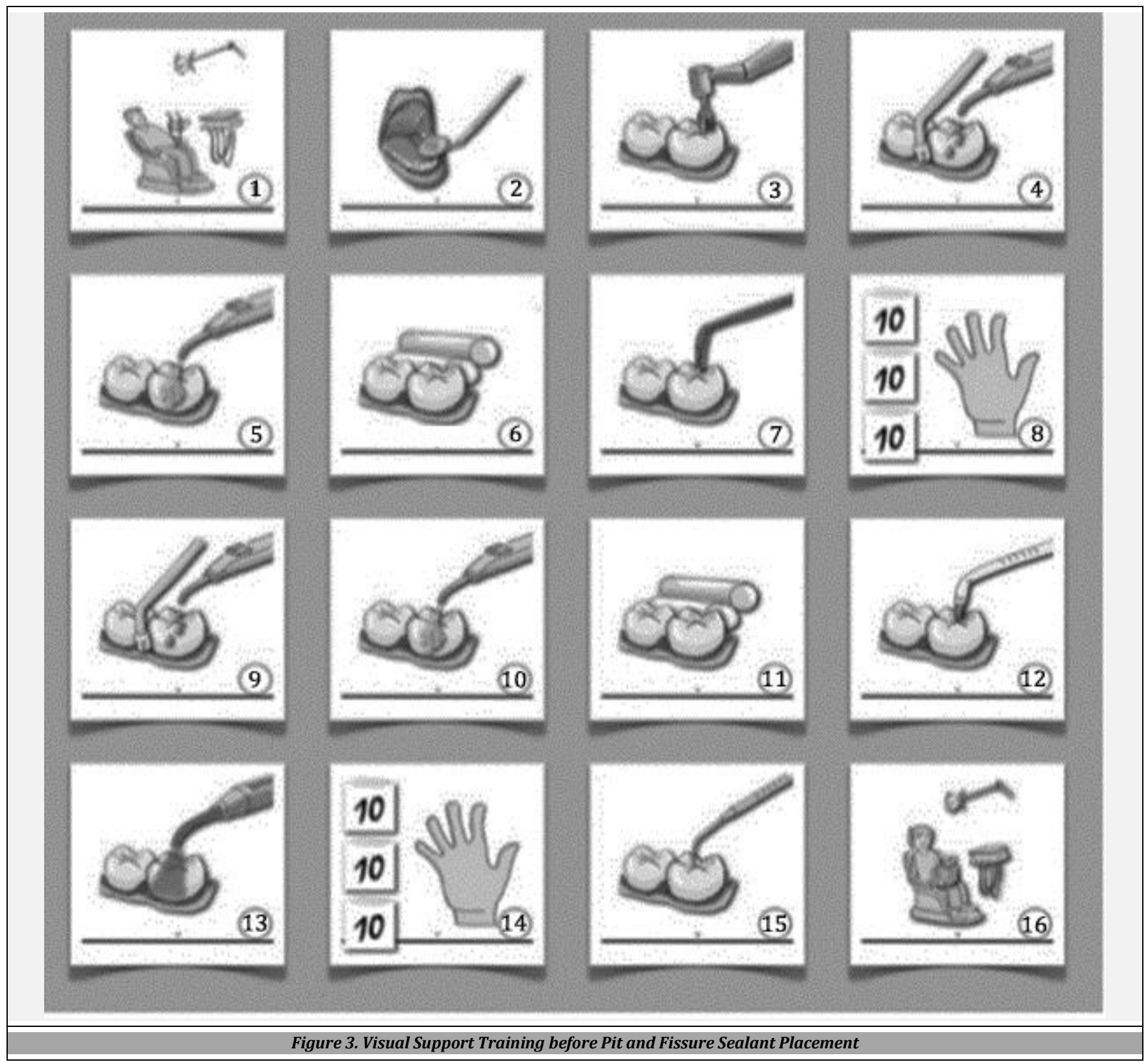

\section{Social Stories}

Children with autism have difficulties in identifying social cues such as body language, facial expressions, eye contact etc. The concept of social stories was developed in 1991 by Carol Gray to teach children with ASD about the social behaviours expected in specific settings like supermarket, playground as well as in a dental clinic. This method involves formulating a story in written, video or as picture illustrations according to the individual needs of the child keeping in mind their age and aptitude. The story is read out to the child every day until the child understands the social situation or learns the behaviour.

\section{Picture Exchange Communication System (PECS)}

It is a distinct form of augmentative and alternative communication (AAC). The AAC is developed and widely used for learners with ASD which aids in improving their communication skills. It is used for children who have limited communication abilities as well as in those whose needs are not adequately met by their current method. It caters to the needs of these children to have a structured routine by use of sequential picture cards to demonstrate an activity.

A recent meta - analysis supported the prospect that PECS is a promising interventional method for children with ASD. 42 Positive change in behaviour as well as decrease in the dependence on parent's / care givers to maintain oral hygiene was observed in children where PECS based interventions were used (Figure 2). ${ }^{43}$ It also helps in smooth communication between the patient and the dentist during preventive procedures (Figure 3). ${ }^{44}$

\section{Visual Pedagogy}

Visual pedagogy is conventionally used as a nonpharmacological behaviour management strategy in a dental clinic. Audio Visual (AV) distraction, especially during the first few dental visits help to break the communication barrier. This works on the fundamental concept of introducing and desensitizing the child by visual, auditory, and tactile 
stimulations in a favourable setting. Video modelling leverages on the ability of autistic children to learn through observation. This technique involves watching video tapes of adults, peers or the children themselves engaging in a behaviour that is being taught. These behaviour modification approaches encourage a positive change in behaviour in children with ASD. Along with being an effective behaviour modification tool AV distraction also causes a significant reduction in anxiety and apprehension during dental procedures. 45 The use of video eyewear might provide better distraction than watching video projected on a conventional screen. ${ }^{46}$

\section{Communicative Behaviour Management Techniques}

Methods such as Tell Show Do, voice control, positive and negative reinforcements enable the dentists to communicate with autistic children to undergo dental examination. However, these methods should be made flexible and modified according to the behaviour and the individual needs of each child. The use of verbal praise as the child accomplishes each step and the use of short, simple sentences are recommended. ${ }^{2}$ If the child is unable to understand verbal communication, nonverbal cues is a good way of enhancing positive behaviour. Methods such as hand over mouth exercise is not recommended as it may be misconstrued as an assault. 47

\section{Pharmacological Approaches}

Patients with ASD having moderate to severe behavioural problems who do not respond well to non-pharmacological behaviour management strategies are treated in the dental office by using advanced behaviour management techniques such as by using physical restraints or with pharmacologic methods like sedation or general anesthesia. 48

Before selecting the drug of choice for conscious sedation, it is recommended that a thorough medical history is recorded, especially for the presence of any systemic conditions and check drug interactions. Data regarding the previous uses of this sort of pharmaceutical agent should be available along with presence of any allergies if noticed. $\mathrm{N}_{2} \mathrm{O}-\mathrm{O}_{2}$ analgesia appears to be beneficial, either alone or as an adjunct to other medications. ${ }^{49}$ In a crossover design study on 13 autistic patients aged 5 - 15 years, both diazepam and midazolam were shown to be effective sedative agents, which were successfully and safely used to sedate autistic patients for dental treatment. Midazolam was significantly more effective than diazepam in those portions of the procedure with increased stimulation. ${ }^{50}$

However, treatment under general anaesthesia should never be the first choice and should only be considered if all other approaches fail.

\section{CONCLUSIONS}

As each and every child is unique, there is no particular formula that suits all. Care must be taken to understand the needs of the child by thoroughly recording the child's behaviour as well as medical history. A combination of approaches can be used for the management of a child with ASD which shouldn't be guided by instinct and creativity rather than a strict rule. Care must be taken for the patient and make the dental experience of the child a pleasant one.

Financial or other competing interests: None.

Disclosure forms provided by the authors are available with the full text of this article at jemds.com.

\section{REFERENCES}

[1] Barbaresi WJ, Katusic SK, Voigt RG. Autism: a review of the state of science for paediatric primary health care clinicians. Arch Pediatr Adolesc Med 2006;160(11):116775.

[2] Loo CY, Graham RM, Hughes CV. Behaviour guidance in dental treatment of patients with autism spectrum disorder. Int J Paediatr Dent 2009;19(6):390-8.

[3] Houston R, Frith U. Autism in history: the case of hugh blair of borgue. Oxford: Wiley-Blackwell 2000: p. 207.

[4] Bohnenberger A. Hans Asperger (1906-1980). The Embryo Project Encyclopedia. Arizona: Arizona State University. (Updated 2018 Jul 3; cited 2016 Aug 27).

[5] Kanner L. Autistic disturbances of affective contact. Nervous Child 1943;2:217-50.

[6] Baker S, Grandin T, Bauman M, et al. Infantile autism: the syndrome and its implications for a neural theory of behavior by Bernard Rimland. 2nd edn. London: Jessica Kingsley Publishers 2015.

[7] Liu J, Nyholt DR, Magnussen P. A genome wide screen for autism susceptibility loci. Am J Hum Genet 2001;69(2):327-40.

[8] Shao Y, Wolpert CM, Raiford Kl. Genomic screen and follow up analysis for autistic disorder. Am J Med Genet 2002;114(1):99-105.

[9] Jamain S, Quach H, Betancur C. Mutations of the x-linked genes encoding neurologins NLGN3 and NLGN4 are associated with autism. Nat Genet 2003;34(1):27-9.

[10] Sandin S, Hultman CM, Kolevzon A, et al. Advancing maternal age is associated with increasing risk for autism: a review and meta-analysis. J Am Acad Child Adolesc Psychiatry 2012;51(5):477-86.e1.

[11] Rekha CV, Arangannal P, Shahed H. Oral health status of children with autistic disorder in Chennai. Eur Arch Paediatr Dent 2012;13(3):126-31.

[12] Centers for Disease Control and Prevention. Facts about ASDs. Children assessed by the ASSQ (Autism Spectrum Screening Questionnaire). Journal of Child Psychology and Psychiatry and Allied Disciplines 2011;4:167-75.

[13] Centers for Disease Control and Prevention (CDC). Mental health in the United States: parental report of diagnosed autism in children aged 4-17 years-United States 20032004. MMWR Morb Mortal Wkly Rep 2006;55(17):481-6.

[14] Centers for Disease Control and Prevention. Prevalence of autism spectrum disorders-autism and developmental disabilities monitoring network, 14 sites, United States, 2002. MMWR Surveill Summ 2007;56(1):12-28.

[15] Raina S, Kashyap V, Bhardwaj A, et al. Prevalence of autism spectrum disorders among children (1-10 years of age)-findings of a mid-term report from Northwest India. J Postgrad Med 2015;61(4):243-6. 
[16] Rudra A, Belmonte MK, Soni PK, et al. Prevalence of autism spectrum disorder and autistic symptoms in a school-based cohort of children in Kolkata, India. Autism Res 2017;10(10):1597-605.

[17] American Psychiatric Association. Diagnostic and statistical manual of mental disorders. $5^{\text {th }}$ edn. Washington, DC: American Psychiatric Association 2013;88-90.

[18] American Academy of Pediatric Dentistry Council on Clinical Affairs. Policy on use of a caries-risk assessment tool (CAT) for infants, children and adolescents. Pediatr Dent 2008-2009;30(7 Suppl):29-33.

[19] Shapira J, Mann J, Tamari I, et al. Oral health status and dental needs of an autistic population of children and young adults. Spec Care Dentist 1989;9(2):38-41.

[20] Friedlander AH, Yagiela JA, Paterno VI, et al. The neuropathology, medical management and dental implications of autism. J Am Dent Assoc 2006;137(11):1517-27.

[21] Shaner JW, Kimmes N, Saini T, et al. Meth mouth: rampant caries in methamphetamine abusers. AIDS Patient Care STDS 2006;20(3):146-50.

[22] Kalyoncu IO, Tanboga I. Oral health status of children with autistic spectrum compared with non-authentic peers. Iran J Public Health 2017;46(11):1591-3.

[23] Udhya J, Varadharaja MM, Parthiban J, et al. Autism Disorder (AD): an updated review for paediatric dentists. J Clin Diagn Res 2014; 8(2):275-9.

[24] Lowe 0, Lindemann R. Assessment of the autism patient's dental needs and ability to undergo dental examination. ASDC J Dent Child 1985;52(1):29-35.

[25] Kamen S, Skier J. Dental management of the autistic child. Spec Care Dentist 1985;5(1):20-3.

[26] Muthu MS, Prathibha KM. Management of a child with autism and severe bruxism: a case report. J Indian Soc Pedod Prev Dent 2008;26(2):82-4.

[27] Saemundsson SR, Roberts M. Oral self-injurious behavior in the develop-mentally disabled: review and a case. ASDC J Dent Child 1997;64(3):205-9.

[28] Lai B, Milano M, Roberts MW, et al. Unmet dental needs and barriers to dental care among children with autism spectrum disorders. J Autism Dev Disord 2012;42(7):1294-303.

[29] Barry S, O' Sullivan EA, Toumba KJ. Barriers to dental care for children with autism spectrum disorder. Eur Arch Pediatr Dent 2014;15(2):127-34

[30] Rade RE. Controversial issues in treating the dental patient with autism. J Am Dent Assoc 2010;141(8):94753.

[31] Reichelt K, Nødland M, Høien T. Autistic syndromes and diet: a follow-up study. Scand J Educ Res 1995;39(3):22336.

[32] Knivsberg AM, Reichelt KL, Høien T, et al. A randomised, controlled study of dietary intervention in autistic syndromes. Nutr Neurosci 2002;5(4):251-61.

[33] Knivsberg AM, Reichelt KL, Høien T, et al. Effect of a dietary intervention on autistic behavior. Focus Autism Other Dev Disab 2003;18(4):248-57.

[34] Whiteley P, Haracopos D, Knivsberg AM, et al. The scan brit randomised, controlled, single-blind study of a gluten-and casein-free dietary intervention for children with autism spectrum disorders. Nutr Neurosci 2010;13(2):87-100.

[35] Pennesi CM, Klein LC. Effectiveness of the gluten-free, casein-free diet for children diagnosed with autism spectrum disorder: based on parental report. Nutr Neurosci 2012;15(2):85-91.

[36] Shapiro M, Sgan-Cohen HD, Parush S, et al. Influence of adapted environment on the anxiety of medically treated children with developmental disability. J Pediatr 2009;154(4):546-50.

[37] Geretsegger M, Elefant C, Mössler KA, et al. Music therapy for people with autism spectrum disorder. Cochrane Database Syst Rev 2014;2014(6):CD004381.

[38] Cermak SA, Duker LIS, Williams ME, et al. Sensory adapted dental environments to enhance oral care for children with autism spectrum disorders: a randomized controlled pilot study. J Autism Dev Disord 2015;45(9):2876-88.

[39] Edelson SM, Edelson MG, Kerr DC, et al. Behavioral and physiological effects of deep pressure on children with autism: a pilot study evaluating the efficacy of Grandin's hug machine. Am J Occupation Ther 1999;53(2):145-52.

[40] Hidayatullah T, Agustiani H, Setiawan A. Behavior management-based applied behaviour analysis within dental examination of children with autism spectrum disorder. Dent J (Majalah Kedokteran Gigi) 2018;51(2):71-5.

[41] Burkhart N. Understanding and managing the autistic child in the dental office. Dent Hyg (Chic) 1984;58(2):603.

[42] Ganz JB, Davis JL, Lund EM, et al. Meta-analysis of PECS with individuals with ASD: investigation of targeted versus non-targeted outcomes, participant characteristics and implementation phase. Res Dev Disabil 2012;33(2):406-18.

[43] Pilebro C, Backman B. Teaching oral hygiene to children with autism. Int J Paediatr Dent 2005;15(1):1-9.

[44] Cagetti MG, Mastroberardino S, Campus G, et al. Dental care protocol based on visual supports for children with autism spectrum disorders. Med Oral Patol Oral Cir Bucal 2015;20(5):e598-604.

[45] Fakhruddin KS, El Batawi HY. Effectiveness of audiovisual distraction in behavior modification during dental caries assessment and sealant placement in children with autism spectrum disorder. Dent Res J (Isfahan) 2017;14(3):177-82.

[46] Fakhruddin KS, El Batawi H, Gorduysus MO. Effectiveness of audiovisual distraction eyewear and computerized delivery of anesthesia during pulp therapy of primary molars in phobic child patients. Eur J Dent 2015;9(4):470 5 .

[47] Newton JT, Shah S, Patel H, et al. Non-pharmacological approaches to behaviour management in children. Dent Update 2003;30(4):194-9.

[48] Hernandez P, Ikkanda Z. Applied behavior analysis: behavior management of children with autism spectrum disorders in dental environments. J Am Dent Assoc 2011;142(3):281-7.

[49] Braff MH, Nealon L. Sedation of the autistic patient for dental procedures. ASDC J Dent Child 1979;46(5):404-7. 
[50] Pisalchaiyong T, Trairatvorakul C, Jirakijja J, et al. Comparison of the effectiveness of oral diazepam and midazolam for the sedation of autistic patients during dental treatment. Pediatr Dent 2005;27(3):198-206. 